\title{
Portfólio reflexivo como método de avaliação na residência de gerência de serviços de enfermagem
}

\section{Reflexive portfolio as method of evaluation in residence in management of the nursing services}

\author{
Eloá Otrenti ${ }^{1}$, Denise Albieri Jodas ${ }^{2}$, Larissa Gutierrez da Silva ${ }^{2}$, Thamy \\ Kronemberger da Cruz Aguilera ${ }^{3}$, Marli Terezinha Oliveira Vannuchi ${ }^{4}$
}

\section{Resumo}

Portfólio Reflexivo é um conjunto de registros realizados por estudantes a respeito de suas vivências no processo ensino-aprendizagem. Este trabalho tem como objetivo descrever o significado do uso do Portfólio Reflexivo como método de avaliação no curso de Residência em Gerência dos Serviços de Enfermagem da Universidade Estadual de Londrina-PR. A dinâmica dessa vivência compõe-se de três partes principais: (1) como cheguei ao curso, (2) situações de ensino e (3) minha aldeia. A utilização dessa metodologia de avaliação não se restringiu apenas ao arquivamento de trabalhos, mas sim como espaço de reflexão dos residentes em relação ao seu cotidiano e oportunidade de teorização da prática. A experiência adquirida resultou em importante ingrediente para melhoria das atitudes em situações práticas, e estimulou, assim, mudança de comportamento e transformação da conduta profissional.

Palavras-chave: Metodologias ativas. Educação. Portfólio.

\begin{abstract}
Reflective Portfolio is a set of registers carried through students about their experiences in the process teach-learning. The objective of this work was to describe the meaning of the Reflective Portfolio use as method of evaluation in the Nursing Management Residence course. The dynamics of this experience is composed in three main parts: (1) "how I arrived at the course", (2) "education situations" and (3) "my village". The use of this methodology of evaluation was not restricted only to the filling of works, but a space of reflection about daily and chance of praxis theoretical. Finally, the experience of this instrument resulted in important ingredient for improvement of the attitudes in practical situations, stimulating, change of behavior and transformation of the professional behavior.
\end{abstract}

Keywords: Active learning. Education. Portfolio.

Mestre em Ciências pelo Programa de Pós Graduação em Gerenciamento de Enfermagem da Escola de Enfermagem da USP.

Mestre em Enfermagem pela Universidade Estadual de Maringá

Residente em Gerência dos Serviços de Enfermagem no biênio 2007-2008.

4 Enfermeira. Doutora em Saúde Pública. Docente do Departamento de Enfermagem da Universidade Estadual de Londrina-PR. 


\section{Introdução}

Em 2006, foi implantado no Hospital Universitário de Londrina-PR (HUL) o programa de Residência em Enfermagem em cinco modalidades, sendo Gerência de Serviços de Enfermagem, Centro Cirúrgico e Centro de Material, Saúde da Criança, Neonatal e Médico Cirúrgica, com a finalidade de capacitar o enfermeiro para analisar, intervir e modificar o processo de trabalho, quando necessário, levando em conta a complexidade da organização.

Este programa foi estruturado em seis grandes Eixos do Cuidar, nos diversos níveis de atenção à saúde, que se articula em dois momentos: práticas interdisciplinares denominado de tronco comum às cinco áreas do programa, e outro composto de práticas específicas com características multiprofissionais, denominado de área de concentração ou tronco específico, por ser dirigido às especificidades de cada área.

No tronco comum são trabalhados os seguintes temas: metodologia da pesquisa, políticas de saúde, informática em saúde e bioestatística, metodologia da assistência de enfermagem, gerência de serviços de enfermagem, ética e bioética, ocupando 20\% da carga horária total de 5.010 horas. As restantes 4.008 horas são destinadas às atividades práticas, que no caso da residência em gerência, são desenvolvidas no HUL; Hospital Dr. Eulalino de Andrade (Hospital Zona Sul); Hospital Dr. Anísio de Figueiredo (Hospital Zona Norte), Irmandade Santa Casa de Londrina (ISCAL), todos localizados no município de Londrina-PR.

Na teorização do tronco específico da residência em gerência de serviços de enfermagem utilizam-se metodologias ativas de ensino aprendizagem, sendo que a mais utilizada é o relato da prática. Como um dos métodos de avaliação utilizou-se o portfólio reflexivo.

No Centro de Ciências da Saúde da Universidade Estadual de Londrina, desde 1992 são utilizadas metodologias ativas de ensino-aprendizagem, com bastante sucesso e significativa divulgação em periódicos nacionais e internacionais (COLOMBO; BERBEL, 2007).

O presente trabalho tem como propósito relatar o significado do uso do portfólio reflexivo como um dos método de avaliação na residência em gerência dos serviços de enfermagem.

\section{Material e métodos}

Trata-se de um relato de experiência. Para melhor compreensão do uso do portfólio reflexivo no programa de residência em gerência de serviços de enfermagem, foram organizadas as seguintes temáticas: conceituando portfólio, que busca o histórico deste método e define seus conceitos, em seguida, trabalhando com o portfólio, que retrata sua operacionalização na residência supracitada.

\section{Conceituando portfólio}

O portfólio foi inicialmente implantado na educação infantil, por volta de 1990, nos Estados Unidos com o objetivo de registrar e organizar o conteúdo aprendido pelos alunos (SÁ, 2008).

Essencialmente, o portfólio é uma coletânea de trabalhos realizados pelo aluno, agrupado em uma pasta, ao longo de uma disciplina ou mesmo durante anos. Essa coleção permite construir o perfil acadêmico do aluno, refletindo seu crescimento, os temas estudados, as facilidades e dificuldades durante seu processo educativo. Pode ser usado, também, como um arquivo de materiais que o aluno julgar interessante, suas reflexões, situações vivenciadas, impressões sobre a disciplina e muitos outros assuntos. Estas anotações, quando com freqüência, tornam o desenvolvimento desta ferramenta um processo contínuo e dinâmico. A partir disso, fazer uma análise do conteúdo descrito no portfólio abandona a concepção de avaliação quantitativa, pois os processos de aprendizagem são diferentes tornando impossível homogeneizar a 
avaliação.

Pernigotti e Saenger (2000) afirmaram que o portfólio apresenta vantagens sobre a prova tradicional e pode ser utilizado em todos os níveis de ensino (fundamental, médio, superior e pósgraduação), auxiliando a dissolver o grande nó da educação: a avaliação.

De acordo com Sá (2008), o portfólio modifica os padrões tradicionais de avaliação, pois permite a integração do aluno com o professor, a interdisciplinaridade por meio da união de diversos assuntos no mesmo espaço, a avaliação da evolução do aluno, estimula a curiosidade, a independência e a auto-estima.

Quem seleciona qual será o conteúdo do portfólio, sob orientação do docente, é o aluno, permitindo que este perceba o método não apenas como um caderno diário de anotações, mas sim como uma pasta de interesses, comentários, críticas, sugestões, autoavaliação e principalmente de reflexão. Assim ele deve ser chamado de portfólio reflexivo (SÁ, 2008).

Alves (2000) referiu que o importante não é o portfólio em si, mas o que o aluno pode aprender durante sua criação e registro das situações que considerem significativas. A confecção do portfólio reflexivo permite atingir os quatro pilares da educação conforme a Comissão Nacional da Educação da UNESCO - Organização das Nações Unidas para a Educação, a Ciência e a Cultura: aprender a aprender, aprender a fazer, aprender a ser.

O portfólio reflexivo, ao permitir a anotação de informações e reflexões acerca do vivenciado ou discutido em sala de aula, desperta curiosidade e interesse pela pesquisa, focando o aluno como principal responsável pelo processo de aprendizagem (SÁ, 2008; MOULIN, 2002).

Cunha e Sanna (2007) observaram, a partir de uma pesquisa sobre o uso do portfolio em um grupo de pesquisa de 35 alunos, que esse método foi eficaz para desenvolver pesquisadores, constituindo-se em um espaço para reflexão, planejamento e inserção no grupo. As autoras também apontam as diferentes formas como foram apresentados os portfólios: pastas, CD-ROM, pasta com disquete e até uma caixa com informações importante anotadas em seu interior.

O uso do portfolio reflexivo pode ser um instrumento, que conduza o estudante à descoberta de si próprio perante diversas situações, ao ser uma forte ferramenta para este, e ainda por mesclar o conhecimento de mundo que possui o suporte científico, mediado de interesse para a sua vida pessoal, acadêmica e profissional (SILVA; TANJI, 2008, p. 1).

O uso do portfólio reflexivo permite que o aluno se torne ético, criativo, desenvolva sua habilidade de escrita e seja capaz de refletir sua própria rotina, característica do profissional desejado pelo mercado de trabalho e pelo mundo do trabalho. Ainda permite o desenvolvimento pessoal e profissional tanto de alunos quanto dos professores envolvidos no processo.

Silva e Tanji (2008) afirmaram que a educação moderna foca a formação de profissionais críticoreflexivos capazes de problematizar a realidade e realizar mudanças, participando ativamente do processo de ensino-aprendizagem, tornando-se mais seguros e confiantes.

\section{Trabalhando com o portfólio reflexivo}

O portfólio reflexivo compreende um dos métodos de avaliação da Residência em Gerência de Serviços de Enfermagem do Centro de Ciências de Saúde da Universidade Estadual de Londrina, que se inicia no módulo específico do $1^{\circ}$ ano com duração de aproximadamente três meses. Sua utilização se estende até o término da residência.

As aulas ocorreram semanalmente com o grupo de quatro residentes de Enfermagem sob coordenação de uma docente (tutora). Na primeira aula, foi apresentada a dinâmica dos temas a serem estudados e a forma de organização do portfólio. 
Salientou-se que o portfólio reflexivo não se trata apenas de arquivamento de papéis ou diário dos fatos, mas sim de uma reflexão analítica da situação teórica interrelacionada com a prática, seja esta vivenciada pelo aluno que o confecciona ou por colegas do grupo. A estrutura acordada entre os participantes compõe-se de três divisórias, sugerida também em Brasil (2005):

1.Como cheguei ao curso $\rightarrow$ consiste em um relato reflexivo do porquê foi escolhido o curso, como foi o processo seletivo e quais as expectativas no momento. Se o residente quiser, pode-se anexar qualquer documento ou lembrança deste momento;

2.Situações de ensino $\rightarrow$ é o arquivamento dos relatos da prática discutidos em sala com conseqüente teorização (sínteses provisórias e definitivas). Tudo o que se discute na teoria deve fazer parte desta segunda parte.

3.Minha aldeia $\rightarrow$ representa de onde o estudante veio, onde mora, com quem mora, espaço de trabalho, dificuldades de relacionamento, etc. Aqui o aluno faz as suas reflexões semanais tendo como foco a relação da teoria e da prática vivenciada no seu cotidiano.

No primeiro ano de residência, nos primeiros encontros do tronco específico, aplica-se a metodologia ativa do relato da prática, e nela os residentes elaboram um relato com base nos problemas vivenciados na prática, e trazem para sala de aula cópias sem a identificação de autoria. Os relatos são lidos por todos e escolhido aquele de maior interesse educacional, ou seja, aquele que revela uma situação potencialmente significativa para o grupo. Esse problema é explorado, com base nos saberes prévios do grupo e em seguida são formuladas questões de aprendizagem direcionadas a checar ou fundamentar as hipóteses levantadas. Os residentes, individualmente, vão buscar respostas na literatura para as questões levantadas e retornam em outro momento, em sala de aula, para socializar as informações levantadas e em grupo faz nova discussão o que permite a construção de novos conhecimentos.
Cada residente constrói as suas sínteses provisórias baseadas no conteúdo estudado e após a socialização em sala é escolhido um residente para elaborar a síntese definitiva a respeito do tema levantado pelo grupo. O objetivo maior é promover a reflexão e correlação teórico-prática das atividades gerenciais e assistenciais.

Todo este rico material de estudo é arquivado no portfólio reflexivo de cada residente.

Além disso, foram realizados os relatos reflexivos dos campos de estágio, envolvendo conquistas e desafios no processo de trabalho, processo ensino-aprendizagem e até mesmo auto-avaliação, correlacionando sempre a prática com a teoria.

Inicialmente, surgiram algumas dificuldades de elaboração, procura de textos, de escrita e principalmente "passar para o papel" as reflexões das vivências. No entanto, com o estímulo e orientação da tutora as dúvidas se transformaram em novo aprendizado. Este sentimento se confirma em uma pesquisa feita por Silva e Tanji (2008), no qual em princípio os alunos pareceram motivados com o novo método, mas diante de algumas dificuldades foram se frustrando. Porém, com orientações e motivações, conseguiram desenvolver bem a proposta. Isso mostra que o portfólio aproxima o estudante do seu tutor numa postura de construção.

O portfólio como método de avaliação, faz com que professor e aluno atuem em parceria, sem com isso se perder o rigor e a seriedade que a atividade impõe. Pelo contrário, a avaliação torna-se mais exigente devido à sua transparência.

\section{Considerações Finais}

A expectativa na utilização do portfólio é de conseguir mobilizar o estudante para a responsabilidade pessoal sobre seu processo de aprendizagem, favorecendo a análise de singularidades e peculiaridades do 
desenvolvimento de cada um.

Durante a confecção do portfólio, desenvolvemos e teorizamos nossa própria ação, estimulando pensamento crítico, criatividade, auto-avaliação (pela constante reflexão), capacidade de articular, de solucionar problemas complexos, de conduzir pesquisa, de desenvolver projetos, formular seus próprios objetivos para a aprendizagem. Somos preparados para a resolução de problemas que surgem diariamente na prática profissional e com isso transformar a nossa prática.

Além disso, essa metodologia institui a pedagogia das perguntas, semeia dúvidas epistemológicas, possibilita autonomia intelectual, pois tira o foco do ensino no educador. Não é uma avaliação classificatória nem punitiva, analisa-se o progresso do aluno e substitui as provas estressantes da avaliação tradicional.

Para nós, a utilização dessa metodologia de avaliação não se restringiu apenas ao arquivamento de trabalhos, mas sim em espaço de reflexão dos residentes em relação ao seu cotidiano e oportunidade de teorização da prática. Por fim, a experiência desse instrumento resultou em importante ingrediente para melhoria das atitudes em situações práticas, estimulando, assim, mudança de comportamento e transformação da conduta profissional.

\section{Referências}

ALVES, L. P. Portfolios como instrumentos de avaliação dos processos de ensinagem. In: REUNIÃO ANUAL da ANPED, 26, 2003, Poços de Caldas. Anais... Poços de Caldas: ANPED, 2003. Diponivel em: <http://www. anped.org.br/reunioes/26/trabalhos/leonirpessatealves.rtf >. Acesso em: 19 ago. 2011.

BRASIL, Ministério da Saúde. Caderno do especializando. Brasília: Fundação Oswaldo Cruz, 2005.

COLOMBO, A. A.; BERBEL, N. A. N. A metodologia da problematização com o arco de Manguerez e sua relação com os saberes de professores. Semina: ciências sociais e humanas, Londrina, v. 28, n. 2, p. 121-146, 2007.

CUNHA, I. C. K. O.; SANNA, M. C. Portfolio como estratégia de avaliação de desempenho de integrantes de um grupo de pesquisa. Revista Brasileira de Enfermagem, Brasília, v. 60, n. 1, p. 73-76, jan./fev. 2007.

GOULART, L. B. AVILA, V. M. Z. O portfólio pode muito mais do que uma prova. Pátio: Revista Pedagógica, Porto Alegra, ano 3, n. 12, p. 54-56, fev./abr. 2000.

MOULIN, N. Utilização do portfolio na avaliação do ensino a distância. ABED, 2002. Disponível em: $<$ http://www2.abed.org.br/visualizaDocumento. asp?Documento_ID=90>. Acesso em: 11 out. 2008.

PERNIGOTTI, J.; SAENGER, L. O portfolio pode muito mais do que uma prova. Pátio, Porto Alegre, ano 3, n. 12, p. 54-56, fev./abr. 2000.

SÁ, I. P. Avaliação por portfolio ou "nem só de provas vive a escola". Disponível em: <http://magiadamatematica. com/uerj/licenciatura/05-portfolio1.pdf $>$. Acesso em: 8 dez. 2008.

SILVA, C. M. S. L. M. D; TANJI, S. O portfolio reflexivo: pareceres dos estudantes de enfermagem. Revista Iberoamericana de Educación, Madrid, v. 6, n. 46, p. 1-10, Jul. 2008.

Recebido em 14 de outubro de 2009 - Received on October 14, 2009

Aceito em 8 de outubro de 2010 - Accepted on October 8, 2010 
